\title{
The interaction of postural systems in visual orientation
}

\author{
N. J. WADE 1 \\ MONASH UNIVERSITY
}

Visual orientation judgments were made during right head tilt, left body tilt, and left trunk tilt, each of $30 \mathrm{deg}$. In these postures the otolith, neck, and trunk systems are stimulated in pairs. The hypothesis that the visual vertical during trunk tilt is equal to the algebraic sum of those in the same direction of body tilt and the opposite head tilt was tested and accepted. This result demonstrates the interaction of these postural systems in visual orientation, and complements the confizmation of the same hypothesis for the visual aftereffect following prolonged tilt.

Visual orientation is precise and accurate when the body is upright. However, it can be influenced systematically by the inclination of the trunk while keeping the head upright (Fischer, 1927; Schöne \& Udo de Haes, 1968; Wade, 1968), or a prior period of head, body, or trunk tilt (Day \& Wade, 1966; Wade, 1968). An analysis of the visual effect and aftereffect from these postures has been made in terms of the otolith (o), neck (n), and trunk $(t)$ receptor systems stimulated (Wade, 1968). These systems are stimulated in pairs during head, body, and trunk tilts. When the same degree of tilt is employed for each posture the relative contributions of these systems to visual orientation can be examined. More specifically, left trunk tilt (L TT) involves trunk stimulation as in left body tilt (L BT), and neck stimulation equivalent to that in right head tilt (R HT). Denoting right tilt as "+" and left tilt as "-.", these values can be expressed symbolically in the following manner:

$$
\begin{aligned}
& \mathrm{L} T T=+\mathrm{n}_{30}-\mathrm{t}_{30} \\
& \text { L BT }=-\mathrm{o}_{30}-\mathrm{t}_{30} \\
& \text { R HT }=+\mathrm{o}_{30}+\mathrm{n}_{30}
\end{aligned}
$$

Assuming that the effects of right and left otolith stimulation are equal and opposite, the neck and trunk stimulation in trunk tilt can be derived by summing the values from head tilt and body tilt:

$$
\begin{aligned}
& \mathrm{RHT}+\mathrm{LBT}=+\mathrm{o}_{30}+\mathrm{n}_{30}-\mathrm{o}_{30}-\mathrm{t}_{30} \\
& =+n_{30}-t_{30} \\
& =\mathbf{L} \text { TT }
\end{aligned}
$$

Therefore, it can be hypothesized that the visual vertical during trunk tilt is equal to the algebraic sum of those in the same direction of body tilt and the opposite head tilt, all of the same degree.

This hypothesis has been accepted for the visual aftereffect following tilt, and was referred to as the "additive hypothesis" (Wade, 1968). However, the otolith system is most probably not involved in the visual aftereffect following tilt (Day \& Wade, 1968), but it is involved in visual orientation during tilt (Correia, Hixson, \& Niven, 1965; Miller \& Graybiel, 1966a, b; Schöne, 1964; Schöne, Parker, \& Mortag, 1967). Thus the assumption that right and left head inclination of the same degree stimulates the otolith system equally and oppositely requires supporting evidence. In the cited experiments, and others involving equal degrees of right and left tilt, no consistent differences have been found in visual orientation, strongly suggesting equivalence of function.

The present experiment was designed to test the additive
Table 1

Means (degrees) for visual vertical with 30 deg right head tilt, left body tilt, and left trunk tilt, together with the mean for the relation between them.

Posture

\begin{tabular}{lllc}
\hline R HT & L BT & L TT & R HT + L BT - L TT \\
-3.80 & +3.06 & -0.71 & -0.03
\end{tabular}

Note: + denotes a CW deviation from gravity; - denotes CCW.

hypothesis for tilt of $30 \mathrm{deg}$. Visual vertical judgments were obtained for each of the three postures, and it was hypothesized that the visual vertical with right head tilt plus that during left body tilt would equal the visual vertical with left trunk tilt.

\section{Apparatus}

\section{METHOD}

The apparatus was the same as that used in a previous study (Wade, 1968). It enabled independent tilting of the head and trunk, so that the postures of head, body, and trunk tilts could be achieved.

\section{Subjects}

Twenty Ss from an introductory course in psychology participated.

\section{Procedure}

The body postures investigated were $30 \mathrm{deg}$ right head tilt, $30 \mathrm{deg}$ left body tilt, and $30 \mathrm{deg}$ left trunk tilt. Two practice trials were given initially with the body upright. Four adjustments to the visual vertical were made during tilt in each posture, from starting positions of $10 \mathrm{deg}$ and $20 \mathrm{deg} \mathrm{CW}$ and CCW of the gravitational vertical. The order of presentation was randomized, and the body was returned to the upright following completion of each judgment, and it remained there for $45 \mathrm{sec}$ before the next tilt. The $S$ 's eyes were closed at all times other than when making an adjustment.

\section{RESULTS AND DISCUSSION}

The visual vertical was averaged over starting positions for each tilt. Table 1 gives the means for the visual vertical for each tilt condition, together with that for the algebraic sum of the visual verticals from right head tilt plus left body tilt minus left trunk tilt. The null hypothesis for the difference of this sum from zero was accepted $(t=0.04, \mathrm{df}=19, \mathrm{p}>.05)$.

For both head and body tilt the Eeffect was obtained, i.e., the visual vertical was on the opposite side of the gravitational vertical to tilt. The magnitude of the E-ffect from head tilt, however, was greater than that from body tilt, and the algebraic sum of the two was almost exactly equal to the visual vertical with left trunk tilt. That is, the additive hypothesis was confirmed for judgments during tilt. This complements the previous acceptance of the hypothesis for the visual aftereffect following prolonged tilt (Wade, 1968). Furthermore, it has been shown that the aftereffect following $15 \mathrm{deg}$ head tilt plus that from $15 \mathrm{deg}$ body tilt is equal to the aftereffect from the combined head and trunk tilt, i.e., with the head tilted 15 deg to the trunk, which was in turn tilted $15 \mathrm{deg}$ to gravity (Day \& Wade, 1969). As noted above, however, the otolith system does 
not appear to be involved in the visual aftereffect from prolonged tilt.

Clearly this additive model can be applied and tested for all tilt combinations. For example, the visual vertical may be predicted for postures involving stimulation of all three systems by determining the influence of each and summing algebraically. The hypothesis has been tested initially for the simplest combination of postures involving the otolith, neck, and trunk systems, i.e., when they are stimulated in pairs.

These studies have demonstrated that for tilts within $30 \mathrm{deg}$ of gravity the involvement of the neck system in visual orientation is greater than that for the trunk. Furthermore, they also indicate how predictions concerning the interaction of the different postural systems involved in visual orientation can be made and tested.

\section{REFERENCES}

CORREIA, M. J., HIXSON, W. C., \& NIVEN, J. I. Otolith shear and the visual perception of force direction: Discrepancies and a proposed resolution. NAMI-95 NASA Order R-93. Pensacola, Fla.: Naval Aerospace Medical Institute, December 1965.

DAY, R. H., \& WADE, N. J. Visual spatial aftereffect from prolonged head-tilt. Science, 1966, 154, 1201-1202.

DAY, R. H., \& WADE, N. J. Involvement of neck proprioceptive system in visual after-effect from prolonged head tilt. Quarterly Journal of Experimental Psychology, 1968, 20, 290-293.
DAY, R. H., \& WADE, N. J. Mechanisms involved in visual orientation constancy. Psychological Bulletin, 1969, 71, 33-42.

FISCHER, M. H. Messende Untersuchungen über die Gegenrollung der Augen und die Lokalisation der scheinbaren Vertikalen bei seitlicher Neigung (des Kopfes, des Stammes, und des Gesamtkörpers). I Mitteilung, Neigung bis zu $40^{\circ}$. v. Graefes Archiv Ophthalmologie, $1927,118,633-680$.

MILLER, E. F., \& GRAYBIEL, A. Role of the otolith organs in the perception of horizontality. American Journal of Psychology, 1966a, 79, 24-37.

MILLER, E. F., \& GRAYBIEL, A. Magnitude of gravitoinertial force, an independent variable in egocentric visual localization of the horizontal. Journal of Experimental Psychology, 1966b, 71, 452-460.

SCHÖNE, $H$. On the role of gravity in human spatial orientation. Aerospace Medicine, 1964, 35, 764-772.

SCHÖNE, H., PARKER, D. E., \& MORTAG, H. G. Subjective vertical as a function of body position and gravity magnitude. Naturwissenschaften, $1967,54,288$.

SCHÖNE, H., \& UDO DE HAES, H. Perception of gravity-vertical as a function of head and trunk position. Zeitschrift für Vergleichenden Physiologie, 1968, 60, 440-444.

WADE, N. J. Visual orientation during and after lateral head, body, and trunk tilt. Perception \& Psychophysics, 1968, 3, 215-219.

\section{NOTE}

1. Present address: Max-Planck-Institut für Verhaltensphysiologie, 8131 Seewiesen, Germany.

(Accepted for publication April 16, 1969.) 